\title{
Editorial
}

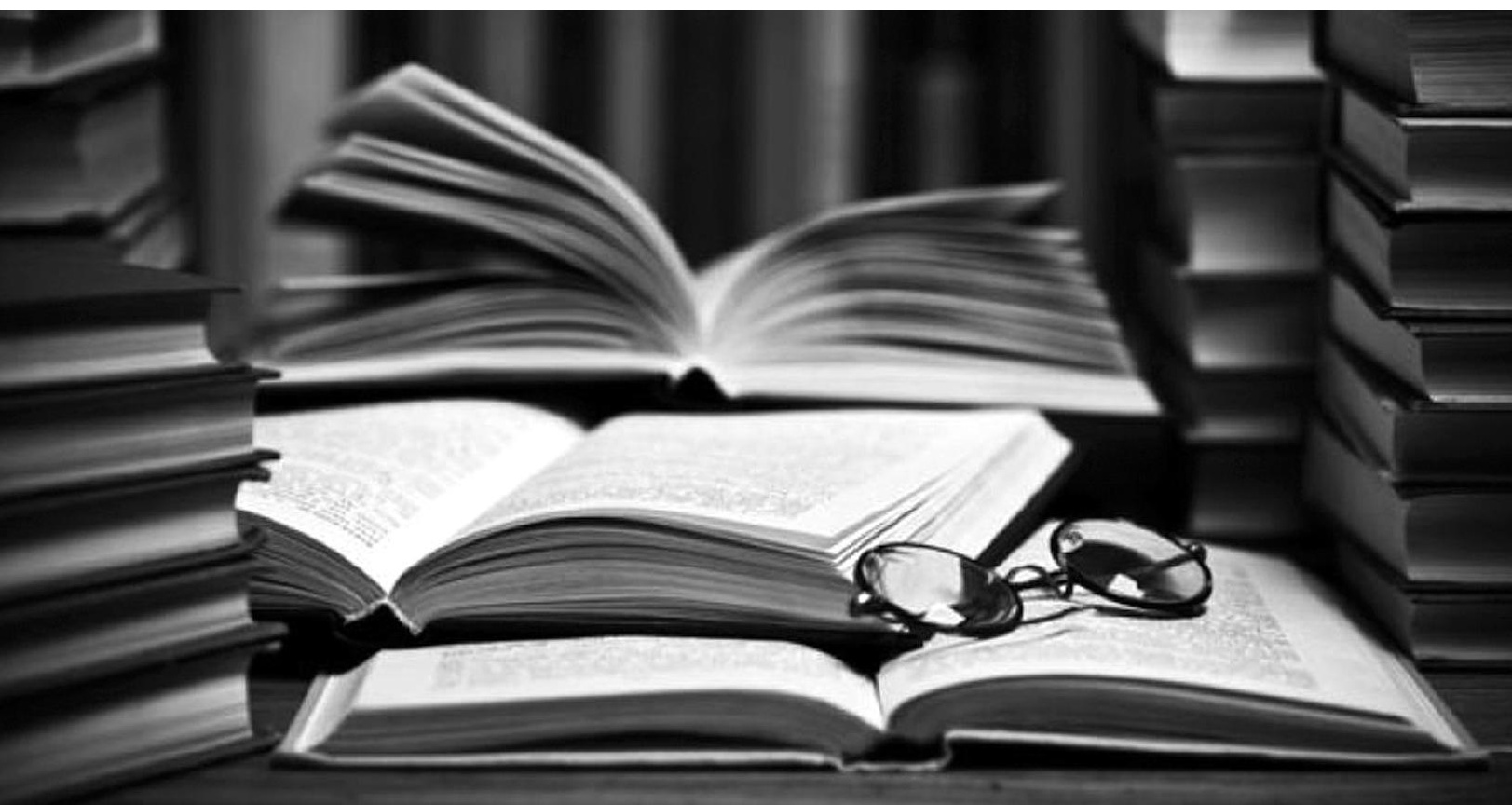





\section{AÑO DE LA ESPERANZA}

Pensar el presente año como el de la esperanza puede parecer quizá demasiado optimista, sin embargo, la época que vivimos de post pandemia puede darnos efectivamente la oportunidad de dejar atrás profundos momentos de obscuridad e incertidumbre y quizá nos impulse a buscar y retomar el camino. Ese camino que nos conduzca a reconstruir nuestras propias realidades.

Es tiempo de reconocernos, compadecernos y reencontrarnos con nosotros mismos. Esa es quizá la mejor forma de mirar el pasado, como aquello que nos deja la oportunidad, a pesar de las terribles perdidas sufridas, de avanzar como sociedad en aras del bien común enalteciendo la dignidad humana como baluarte de la nueva era.

Necesitamos reflexionar en la necesidad de reinterpretar y reconstruir nuestra propia realidad. El mundo se desmorona frente a la economía de mercado, se acentúan las desigualdades, el clasismo está más presente que nunca, los que tienen riqueza ahora pueden mantener la salud y quizá conservar la vida; pero lamentablemente los que carecen de ella, no cuentan con la conveniente atención y protección de la salud, por lo que en muchos de los casos pierden la vida. Este complicado hecho nos coloca frente a una realidad sobre la forma en que hasta ahora se ha administrado la riqueza y nos empuja a lograr una renovada conciencia del ser, tanto individual como colectivamente.

Es verdad que el COVID 19 no hizo diferencias entre edad, sexo ni condición social, pero el cómo se afrontó la pandemia si mostro una gran diferencia entre pobres y ricos, entre quienes tienen un desarrollo humano pleno y asegurado y quienes no tienen ni lo uno ni lo otro. Fácilmente apreciamos como en nuestra sociedad existe una marcada línea que separa a unos de otros, hay quienes tienen servicios de salud, vivienda digna, agua potable, luz, alimentación, educación, vestido, trabajo bien remunerado y por otra parte, hay otros, en su gran mayoría, 
que carece de tales derechos por lo que no les permitió afrontar la pandemia de igual forma a todos.

Aprendimos que países ricos como Alemania incorporaron políticas públicas de rescate para ayudar al sector empresarial e incentivar la economía, así destinaron 145.000 millones de dolares a un plan para compensar la contracción económica, apoyando con ello, a las empresas en donde todos se beneficiaron, así trabajadores, empresarios y el propio Estado al fortalecer la economía.

Otra de las medidas que tomó el gobierno Aleman fue la reducción del IVA, que pasó del 19\% al 16\%; así mismo, se estimuló el consumo de las familias otorgando un bono de 336 dolares por hijo por una única vez.

Ángela Merker destinó 55,000 millones de dólares a un "paquete para el futuro" destinado a inversiones en áreas estratégicas como la enconomía de hidrógeno, las tecnologías cuánticas y la inteligencia artíficial.

Se creó un Fondo de Estabilidad Económica, financiado con más de 110.000 millones de dólares de los contribuyentes para los tiempos de crisis, con la intención de que el Estado sea el impulsor de la economía mediante un rol más activo. Se puso en marcha un programa denominado "Hecho en Alemania: Estratégia industrial 2030" que pretende impulsar la industria para que ocupe el $25 \%$ del grueso de la economía, la cual hoy se situa en el $23.4 \%$ a traves de sectores clave como el aeroespacial, el químico, la ingeniería y el equipamiento médico.

Desde luego resulta admirable que uno de los países más ricos del mundo invierta clara y contundentemente en equilibrar su economía mediante una política pública que protege directamente lo más importante que tiene, que es el bienestar social de sus ciudadanos.

Apostar por un nuevo modelo democrático de bienestar, con una distribución de recursos económicos y sociales equitativamente, lograría disminuir las condiciones de desigualdad, pobreza y rezago social en que vivimos; lo cual vendría acompañado, sin duda alguna, de paz y cohesión social, que al disminuir los altos índices de violencia nos daría un respiro a esta tan abatida sociedad de consumo post pandemia.

Guadalajara, Jalisco, invierno 2021

Dra. Silvia Patricia López González 